\section{Endoscopic Resection of Ampullary Carcinoma}

Endoscopic resection may be an appropriate alternative treatment in selected patients with ampullary tumors $[1,2]$.

An 82-year-old woman was admitted for jaundice, fever, and right upper quadrant abdominal tenderness. Her medical history included a stroke, heart failure, and hypertension. Transabdominal ultrasonography showed a dilated common bile duct and pancreatic duct, with no evidence of biliary lithiasis, pancreatic tumor, or hepatic lesions. Endoscopic retrograde cholangiopancreatography (ERCP) demonstrated a prominent papilla of Vater suspicious for ampulloma (Figure[1a]). Cholangiopancreatography also showed a dilated common bile duct and pancreatic duct, with a stenosis at the level of the sphincter of Oddi, but no intraductal tumor or stones.

After precutting of the papilla, a $10-$ Fr plastic biliary stent was placed, achieving effective drainage. Brush cytology and biopsy of the papilla showed a well-differentiated adenocarcinoma. Endoscopic ultrasonography demonstrated a well-demarcated 14-mm hypoechoic lesion at the papilla, limited to the mucosa and with no local lymph nodes (Figure [ $1 \mathrm{~b}]$ ). The patient declined surgery, but accepted endoscopic resection, which was carried out under sedation with midazolam. Ablation of the tumor was accomplished using a standard polypectomy snare, exposing the pancreatic duct, with copious drainage of pancreatic juice. A 7-Fr stent was placed in the pancreatic duct to prevent pancreatitis. Pathological evaluation of the resected specimen confirmed a well-differentiated adenocarcinoma. The resection margins were free of tumor infiltration.

The patient was discharged 4 days after endoscopic treatment, and was asymptomatic, with normalization of laboratory values. The biliary and pancreatic stents were removed during an ERCP evaluation 1 month after the endoscopic ablation. Endoscopic follow-up examinations were carried after 2, 5, 14 and 24 months, al-
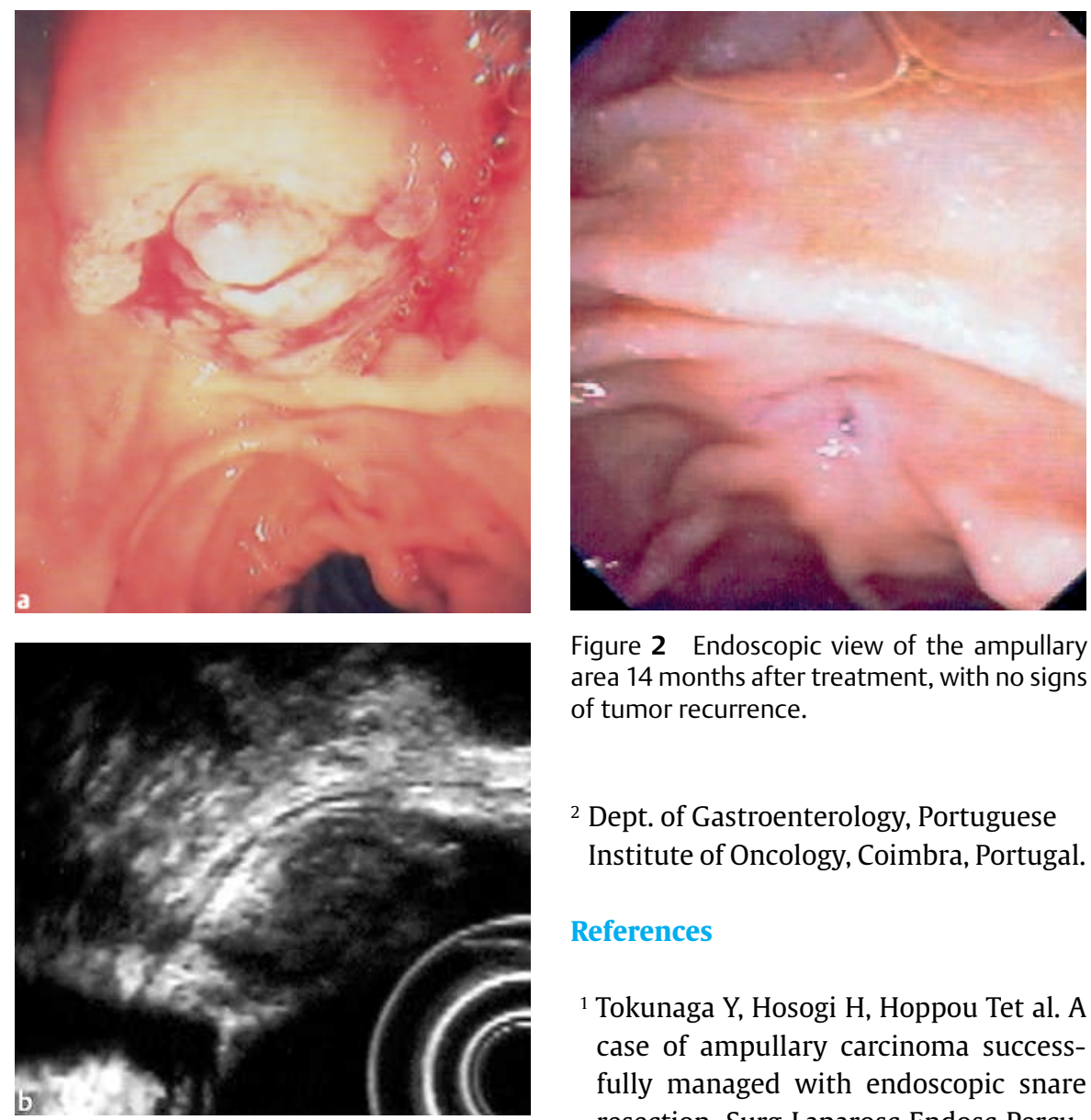

Figure 2 Endoscopic view of the ampullary area 14 months after treatment, with no signs of tumor recurrence.

2 Dept. of Gastroenterology, Portuguese Institute of Oncology, Coimbra, Portugal.

\section{References}

${ }^{1}$ Tokunaga Y, Hosogi H, Hoppou Tet al. A case of ampullary carcinoma successfully managed with endoscopic snare resection. Surg Laparosc Endosc Percutan Tech 2002; 12: 273-278

Figure 1 a A prominent and irregular papilla of Vater, suspicious for ampulloma. b Endoscopic ultrasound shows a small, hypoechoic ampullary lesion, limited to the mucosa, with no local lymph nodes.

ways with biopsy and cytology, and no evidence of recurrent tumor was found. Endoscopic ultrasonography and magnetic resonance cholangiopancreatography carried out after 24 months also did not demonstrate any signs of tumor recurrence (Figure [2]). At the time of writing, the patient had been asymptomatic and without any abnormal laboratory values for a 24-month follow-up period.

P. Neves', M. Leitão' ${ }^{1}$ F. Portela',

J. M. Pontes ${ }^{2}$, M. Areia', D. Brito', H. T. Sousa1, P. Souto', E. Camacho', P. Andrade ${ }^{1}$, H. Gouveia ${ }^{1}$, D. Freitas ${ }^{1}$ ${ }^{1}$ Dept. of Gastroenterology, University Hospitals of Coimbra, Coimbra, Portugal
2 Park SW, Song SY, Chung JBet al. Endoscopic snare resection for tumors of the ampulla of Vater. Yonsei Med J 2000; 41: $213-218$

\section{Corresponding Author}

\section{P. Neves, M.D.}

Dept. of Gastroenterology

University Hospitals of Coimbra

Praceta Professor Mota Pinto

3000 Coimbra

Portugal

Fax: $\quad+351-239-701517$

E-mail: gastro@huc.min-saude.pt 